\title{
Investigation of the benefits of pulse current for the additive manufacture of Ti-6Al-4V
}

\author{
Guangsen Chen ${ }^{1, a}$, Zhenshu Ma ${ }^{2, b}$, Changmeng Liü ${ }^{3, \mathrm{c}}$ \\ ${ }^{1}$ Ordnance Engineering College, Shijiazhuang 050003, China; \\ ${ }^{2}$ Ordnance Technology Institute, Shijiazhuang 050003, China; \\ ${ }^{3}$ Beijing Institute of Technology, Beijing 100081, China. \\ aguangsen_chen@126.com, bmazs@vip.163.com, cliuchangmeng@bit.edu.cn
}

Keywords: additive manufacturing, Ti-6Al-4V, pulse current

\begin{abstract}
In order to reduce the heat input in arc additive manufacturing, pulse current was adopted. Single-layer beads and multi-layer walls were deposited by direct current and pulse current. The morphology, microstructure and mechanical properties of forming components were analyzed. Experimental results exhibited that the pulse current can reduce the heat input effectively, but it has no obvious impacts on microstructure and mechanical properties of the forming parts.
\end{abstract}

\section{Introduction}

Additive manufacturing (AM), also known as 3D printing, has gained worldwide popularity in recent years. Unlike traditional machining approaches, components are building up layer by layer in AM, which has been proved to be environment-friendly and high-efficiency. Additive manufacturing has a buy-to-fly ratio of 1.15 , while the traditional approach can be as high as $30^{[1]}$. So, Additive manufacturing has wide application prospects in processing some difficult-to-machine and precious materials such as Ti-6Al-4V.

The rapid development of additive manufacturing leads to several techniques, such as selective laser melting (SLM), electron beam melting (EBM) and wire arc additive manufacturing (WAAM). In recent years, WAAM has been a hotspot because of its high productivity, flexibility in materials and ease of automation ${ }^{[2]}$. WAAM uses arc as heat source, including Tungsten inert gas (TIG), Plasma arc welding (PA) and metal inert gas welding (MIG). However, residual stresses and distortions caused by excessive heat input are still the main challenges. Several measures like high-pressure rolling ${ }^{[3]}$ are adopted to reduce the distortions and improve the mechanical properties.

In this study, pulse current is adopted to reduce the heat input in additive manufacturing and relevant parameters are investigated. The microstructure and mechanical properties of the forming parts are discussed as well.

\section{Experimental details}

Fig. 1 shows the schematic of arc additive manufacturing. The titanium substrate is fixed on the workbench which can travel along the $\mathrm{X}-\mathrm{Y}$ direction while the torch can go up and down vertically. 


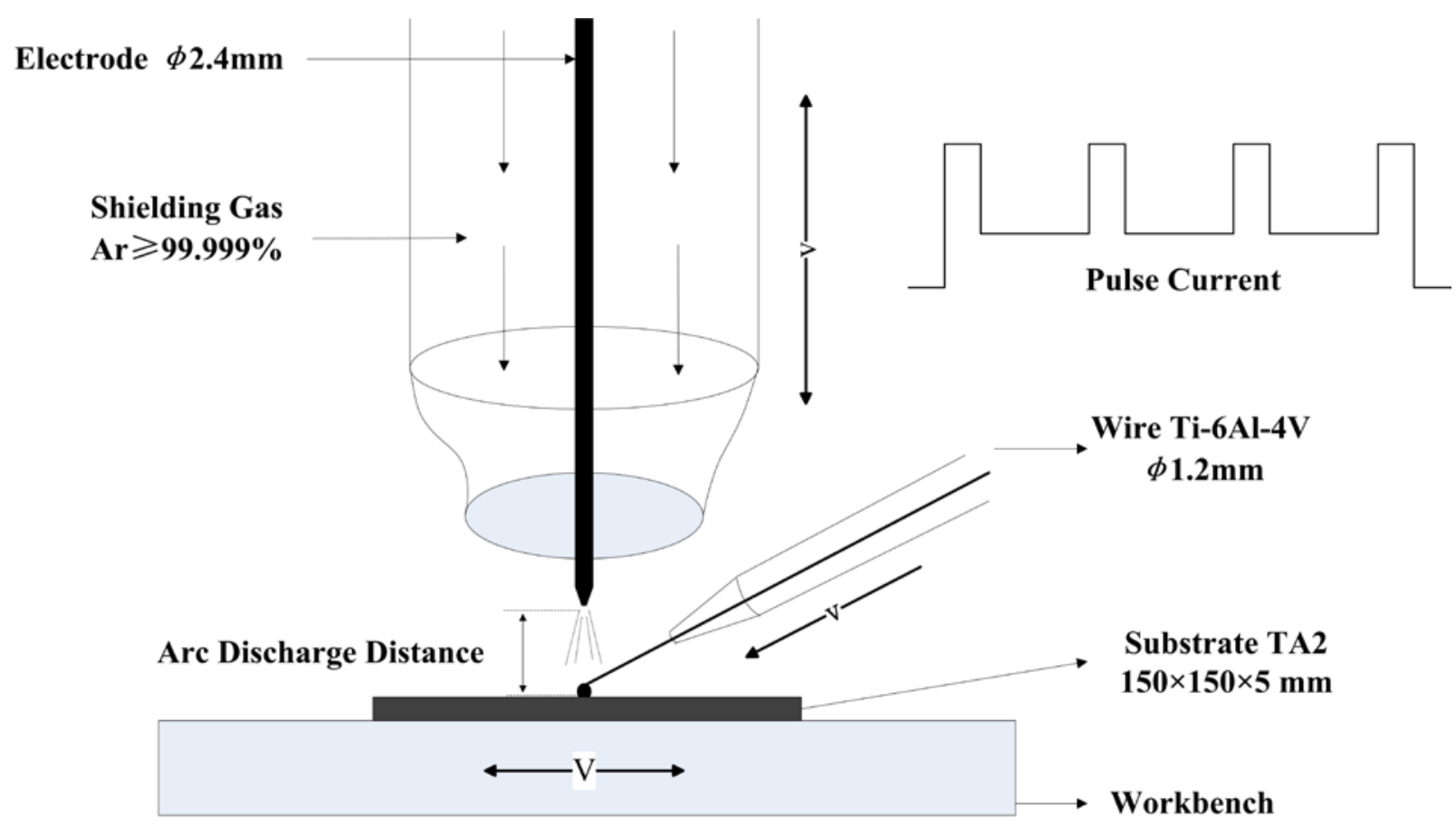

Fig. 1 Process principle of low heat WAAM

The Ti-6Al-4V wire is fed into the melting pool through a copper feed pipe and it is controlled by a wire feeder to ensure stable transportation. The forming processes are protected in argon atmosphere with a purity of $99.999 \%$.

Both direct current (DC) and pulse current (PC) were carried out in this study. The related welding parameters are given in the table 1 , such as scanning speed, peak current, pulse frequency, etc. The current of single-layer beads were selected every other $20 \mathrm{~A}$ from $60 \mathrm{~A}$ to $200 \mathrm{~A}, 8$ values altogether. Multi-layer walls were also deposited by direct current (Fig. 2(a)) and pulse current (Fig. 2(b)) with the parameters list in table 1 . In addition, oscillating wire feed was adopted, which is conducive to the transition of molten drops. The ratio of feeding and quiescent period is 1:1.

Fig. 2(c) gives the dimensions of tensile specimens. Three specimens were manufactured each of the wall by wire-electrode cutting to ensure the data reliable and appropriate data were adopted. The tensile tests were performed in an Instron testing machine at room temperature with displacement rate of $0.01 \mathrm{~mm} / \mathrm{s}$. Video extensometer was used to record the strain. Besides, the optical microstructure was also given.

Table 1 Deposition Parameters

\begin{tabular}{cccc}
\hline Parameters & Single-layer & \multicolumn{2}{c}{ Multi-layer } \\
\cline { 3 - 4 } & & DC & PC \\
\hline Wire feed speed(cm) & 150 & 300 & 100 \\
Scanning speed(mm) & 150 & 300 & 100 \\
Peak current(A) & $60 \sim 200$ & 120 & 80 \\
Peak time(\%) & 30 & - & 30 \\
Background current(\%) & 25 & - & 25 \\
Pulse frequency(HZ) & 8 & - & 8 \\
Gas flow rate $\left(\mathrm{L} \cdot \mathrm{min}^{-1}\right)$ & 20 & 20 & 20 \\
Arc length(mm) & 3 & 3 & 3 \\
\hline
\end{tabular}




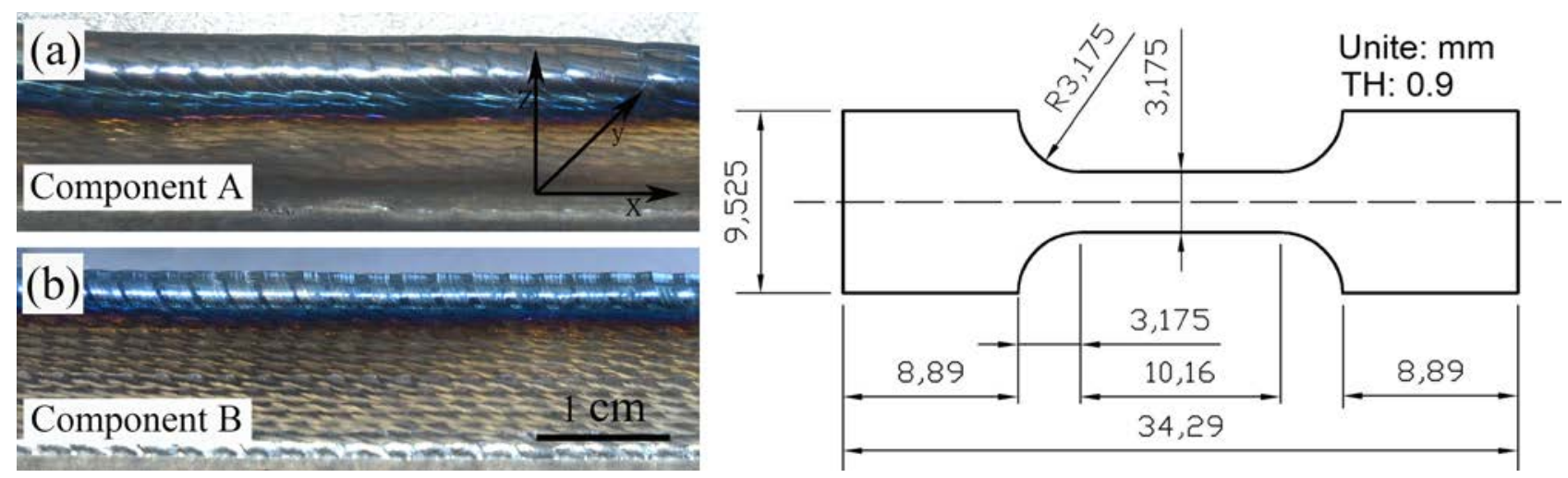

Fig. 2 Deposited walls and tensile specimens

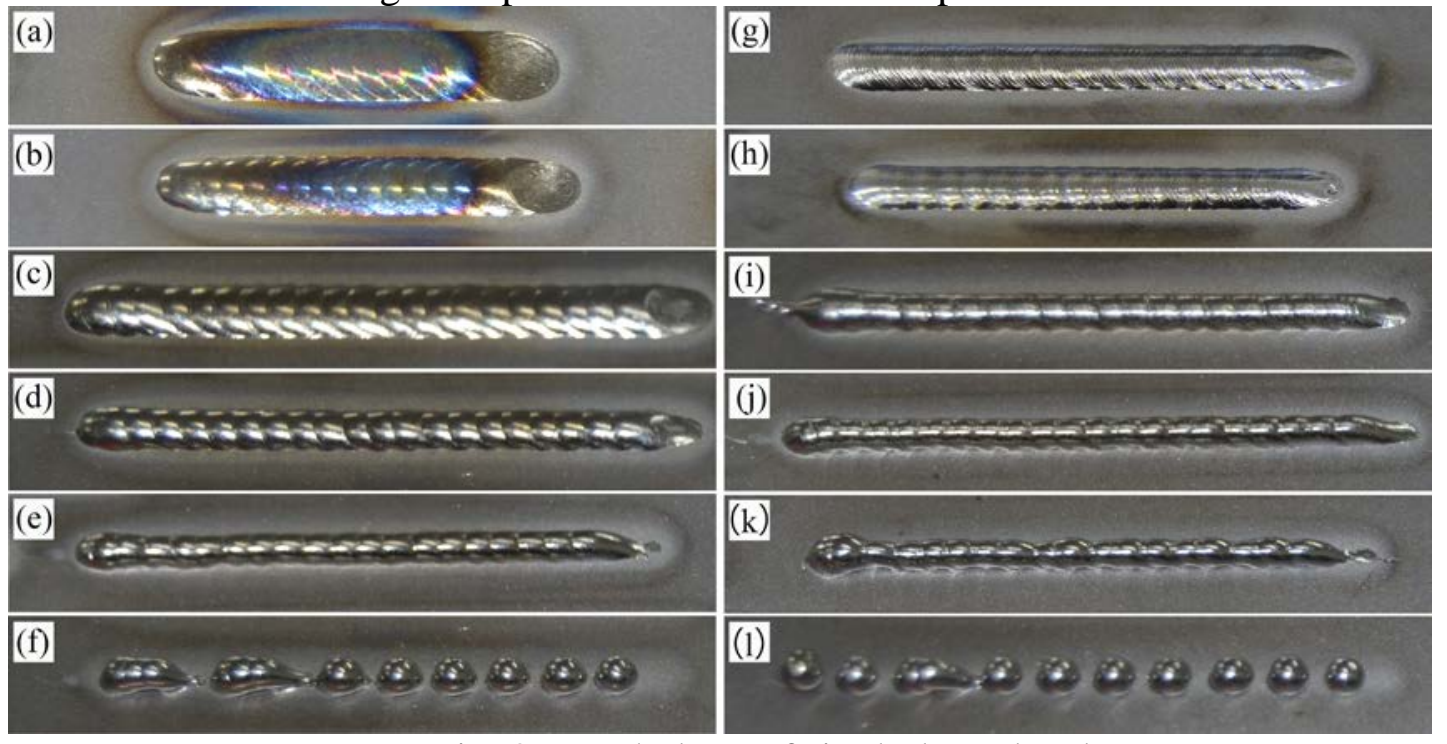

Fig. 3 Morphology of single-layer bead

Table 2 deposition parameters and the resulting geometry

\begin{tabular}{cccccccccc}
\hline $\begin{array}{c}\text { Component } \\
\text { name }\end{array}$ & $\begin{array}{c}\text { Current } \\
(\mathrm{A})\end{array}$ & $\begin{array}{c}\text { Width } \\
(\mathrm{mm})\end{array}$ & $\begin{array}{c}\text { Height } \\
(\mathrm{mm})\end{array}$ & $\begin{array}{c}\text { Heat input } \\
(\mathrm{J} / \mathrm{mm})\end{array}$ & $\begin{array}{c}\text { Component } \\
\text { name }\end{array}$ & $\begin{array}{c}\text { Current } \\
(\mathrm{A})\end{array}$ & $\begin{array}{c}\text { Width } \\
(\mathrm{mm})\end{array}$ & $\begin{array}{c}\text { Height } \\
(\mathrm{mm})\end{array}$ & $\begin{array}{c}\text { Heat input } \\
(\mathrm{J} / \mathrm{mm})\end{array}$ \\
\hline $\mathrm{a}$ & 160 & 8.4 & 0.8 & 742.4 & $\mathrm{~g}$ & 200 & 5.12 & 1.26 & 313.12 \\
$\mathrm{~b}$ & 140 & 6.68 & 1.08 & 613.8 & $\mathrm{~h}$ & 180 & 4.48 & 1.52 & 274.72 \\
$\mathrm{c}$ & 120 & 5.38 & 1.46 & 491.5 & $\mathrm{i}$ & 160 & 3.16 & 1.84 & 237.6 \\
$\mathrm{~d}$ & 100 & 3.9 & 1.72 & 387.2 & $\mathrm{j}$ & 140 & 2.68 & 2.06 & 203.84 \\
$\mathrm{e}$ & 80 & 2.86 & 1.8 & 289.3 & $\mathrm{k}$ & 120 & 2.4 & 2.16 & 172.032 \\
$\mathrm{f}$ & 60 & \multicolumn{2}{c}{ Failed } & 207.4 & $\mathrm{l}$ & 100 & Failed & 141.376 \\
\hline
\end{tabular}

\section{Results and discussion}

Surface Morphology. Table 2 gives the deposition parameters, bead height, width and heat input. Fig. 3 shows the photograph of single-layer beads. Parameters in table 2 corresponds to the images in Fig. 3 with the same component name. The beads of (a) (f) were deposited by direct current and the (g) (l) were deposited by pulse current. Excessive heat input may accelerate the oxidation. As it is shown in the Fig. 3(a) and 3(b), despite the high purity argon atmosphere, some of the beads appear a colorized surface. However, insufficient heat input will lead to spheroidization effect (Fig. 3(f) and 3(l)). Lower heat input may result in larger liquid viscosity, surface tension as well as the less remelting of the substrate. Therefore, spheroidization effect occurred when the direct current is $60 \mathrm{~A}$ and the peak current of pulse current is 100A. However, further studies find that the current can decline to 60A (DC) and 80A (PC) in the following layers due to the cumulative effect of thermal. Since the pulse current can promote the droplet transition, the heat input of pulse current is much lower than the direct current when the spheroidization effect arise (table 2). In other words, pulse current can reduce the heat input in WAAM. 
The relationship between formation of Ti-6Al-4V bead and heat input are investigated. As far as direct current is concerned, with the heat input increasing from 289 to $742 \mathrm{~J} / \mathrm{mm}$, the width of beads increase from 2.9 to $8.4 \mathrm{~mm}$, while the height decreased from 1.8 to $0.8 \mathrm{~mm}$. The tendency of beads deposited by pulse current are the same with direct current. Yet, the heat input of (e) is lower than (h) and (j), but the bead width of (f) and (j) are bigger than (e). Besides, although the peak current of (a) and (i), as well as (b) and (j), (c) and (k) are the same, the width of (a) is much bigger than (i) (Fig. 3). The result shows that the formation of weld bead are mainly depended on the arc temperature. As the peak current increased, the temperature of arc raise, which promotes the melting of Ti-6Al-4V wire and substrate. So that the height and contact angle decreased ${ }^{[4]}$.

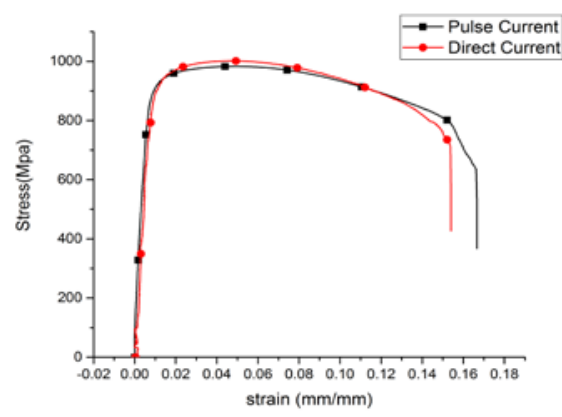

Fig. 4 stress-strain curves

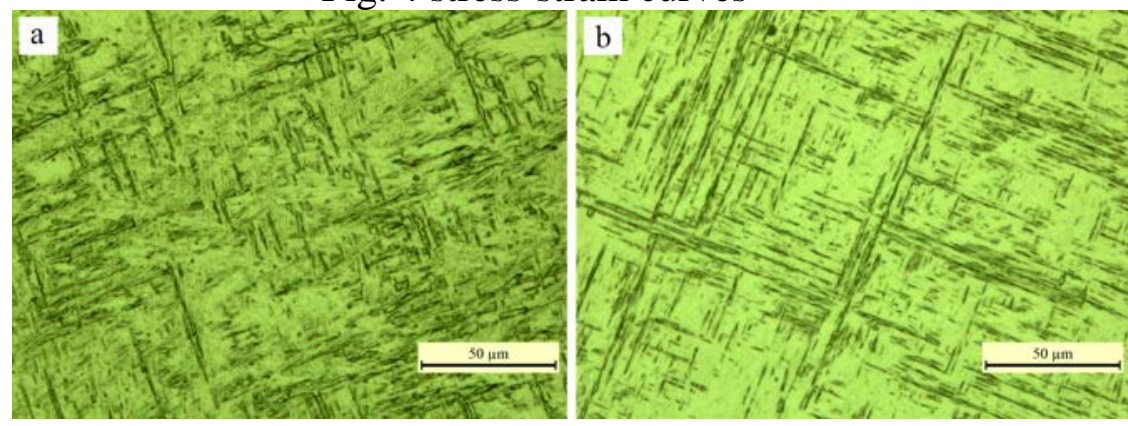

Fig. 5 microstructure of component A and B

Microstructure and Mechanical properties. The stress-strain curves are exhibited in Fig. 4. The UTS of component A (direct current) is $1001 \pm 17 \mathrm{Mpa}$, slightly higher than that of component B (pulse current), which is $983 \pm 19 \mathrm{Mpa}$. Yet, the ductility of B is a little better. In general, no significant differences of tensile property is observed between A and B. Due to the steep thermal gradient and repeated heat input, coarse $\beta$ grains are formed with more than one millimeter in width and even longer in height. The micrograph are fully lamellar structures with martensite and widmanstatten because of high cooling rate. Fig. 5 shows part micrograph of the cross section (y-z). In this study, the size of tensile test specimen is quite small, but the grain size of both components is coarse. As the mechanical properties of fully lamellar structures are affected by microstructure and the most influential parameter is colony size ${ }^{[5]}$. Therefore, it is the morphology of martensite and widmanstatten rather than the colony size that may determine the mechanical properties. The martensitic structure of (b) is finer than (a) in Fig. 5, leading to better UTS and lower ductility, which agree with relevant research ${ }^{[6]}$.

\section{Summary}

The forming ability of pulse current and direct current are compared in this paper. The minimum heat input of pulse current is much lower than direct current when single-layer bead can be formed successfully, i.e., that the pulse current can reduce the heat input. The width and height of the bead are mainly affected by the arc temperature.

Microstructure of the formed components are fully lamellar structures with martensite and widmanstatten. Tensile properties of the components deposited by this two strategies are similar while differences of UTS and ductility are related to the structure of martensite and widmanstatten. 
In general, using pulse current can enhance the forming ability. However, pulse current can't improve the mechanical properties and microstructure of forming parts in this study. Whether pulse current have the other impacts on deposited components still need further research.

\section{References}

[1] Williams, S. W., Martina, F., Addison, A. C., Ding, J., Pardal, G., \& Colegrove, P. (2015). Wire + arc additive manufacturing. Materials Science \& Technology.

[2] Zhang, Y. M., Chen, Y., Li, P., \& Male, A. T. (2003). Weld deposition-based rapid prototyping: a preliminary study. Journal of Materials Processing Technology, 135(s 2-3), 347-357.

[3] Martina, F., Colegrove, P. A., Williams, S. W., \& Meyer, J. (2015). Microstructure of interpass rolled wire + arc additive manufacturing ti-6al-4v components. Metallurgical \& Materials Transactions A, 46(12), 1-16.

[4] Katou, M., Oh, J., Miyamoto, Y., Matsuura, K., \& Kudoh, M. (2007). Freeform fabrication of titanium metal and intermetallic alloys by three-dimensional micro welding. Materials \& Design, 28(7), 2093-2098.

[5] Lütjering, G. (1998). Influence of processing on microstructure and mechanical properties of $(\alpha+\beta)$ titanium alloys. Materials Science \& Engineering A, 243(1-2), 32-45.

[6] Baufeld, B., Biest, O. V. D., \& Gault, R. (2010). Additive manufacturing of ti-6al-4v components by shaped metal deposition: microstructure and mechanical properties. Materials \& Design, 31(1), S106-S111. 